\section{FLAMSTEED REVISITED}

\section{An Account of the Revd. John Flamsteed and a Supple- ment to the Account}

1835/7 facsimile, with an added Author Index 1966. By Francis Baily. Pp. lxxiil +759 . (London: Dawson's of Pall Mall, 1966.) 252s.

THERE is nothing so pathetic as a scholar who cannot afford to buy the books he nocds, unless it is a university which is in the same predicament. Because early (and not so early) scientific books are becoming increasingly collectors' items, it is fortunate that relatively inexpensive methods of reprinting old books are available to meet the needs both of professional historians and of scientists themselves. There are many who would have been eternally grateful for a reasonably priced reprint of Baily's Life of Flamsteed. At last, un some strange economic principle, they have been offered a perfectly ordinary roprint of a shortened version of the book, in a binding which is not the sort which springs to mind when the price of twelve guineas is mentioned. New books, it seems, must not be brought in to redress the prices fetched by the old.

'The Reverend John Flamsteed was the first Astronomer' Royal. Had not a scrap of his writings survived, he would nevertheless have been romembered as the astronomer whose careful observations, in Newton's hands, provided a basis for planetary (and, in particular, lunar) gravitational theory. In 1832 Francis Baily gathered together a large collection of letters and manuscript material in Flamsteed's hand. He classified them, saw that they were carefully preserved, and from them compiled his Life. The biographical parts are composed almost wholly out of Flamsteed's own words, and the sections which follow comprise nearly three hundred letters to and from Flamstcod. "This correspondence", wrote Baily, "embraces a variety of subjects: but the principal, the most novel, and the most interesting, is the account of the repeated difficultics and impediments which delayed and almost prevented the publication of the Historia Caelestis; and the new light which it throws not only on the history of that transaction, but also on the whole of Flamsteed's labours in the science of astronomy."

Both sides of the great quarrel between Flamsteed, Newton and Halley are now well known; but when Baily was writing, one of his most difficult tasks was that of showing that the flaws were not only in Flamsteed's character. Many of his own comments, especially in the Supplement of 1837, here reprinted, were designed to give Flamsteed a fair hearing in an overwhelmingly Newtonian world. Baily also believed that by making a careful study of Flamsteed's computation book, which in turn allowed him to publish in the Life a revised version of the British Catalogue of stars, "much additional light might . . . be thrown on the history of Flamsteed's life and labors . . ." The present publisher, however, in defiance of Baily's wishes, omits this section completely "as irrelevant to a biographical work". This is high-handed and presumptuous: editorial libertios are apparently not thought to carry concomitant duties, for not a word of explanation is given which will allow the twelve-guinea reader to form an idoa of the nature of the missing tables. Baily, of course, was right. The historian who wishes to penetrate tho thin crust of personal anecdote which covers all great men is bound to look for evidence of Flamsteed's worth as the sort of astronomer he set himself up to be. Even his catalogue, standing alone, would have been valuable to the historian. But in Baily's original edition the catalogue was accompanied by 160 pages of critical notes, and prefaced by an invaluable introductory essay of 43 pages. Little service is done to Flamsteed by omitting all this, less is dono to Baily, and least of all to those who want to read Baily's critique of the work of one of the greatest observers in the entire history of astronomy.

$$
\text { J. D. North }
$$

\section{DIFFICULT MATERIAL}

\section{Beryllium}

Its Metallurgy and Properties. Fdited by Henry H. Hausner. Pp. 322. (Berkeley and Los Angeles: University of California Press; London: Cambridge University Press, 1965.) $\$ 9$; 72s. net.

A Book based on a single metallic element may have one or even two authors, or may be compiled by a selected band of specialists led by an editor who is himself one of the specialists. This volume falls into the latter category, and appears none the worse for this treatment, particularly as it is based on an extension course at the University of California, Los Angeles.

From the start, beryllium is treated as a material of construction which has really arrived, although its present disadvantages are not glossed over, and the need for future research and development is adequately emphasized. The editor, in his introduction, emphasizes the outstanding physical properties of this low density metal in the aircraft and nuclear fields, and its use as a valuable alloying element in combination with more conventional metals. Inevitably, the more recent interest in "space applications" has increased the offort in research, particularly where space programmes exist. The table of world production of concentrates stops short at 1962, with a peak in 1960 , the point at which the nuclear interest became most obvious in Britain, France, the United States and the Soviet Union. The volume of production may well now be even greater.

A single chapter is devoted to the extraction of beryllium oxide, and another to the reduction of the oxide to the metal. This latter chapter gives the full thermodynamic argument for the two major commercial processes, namely, magnesium reduction of the fluoride, and low temperature electrolysis of the chloride. Comparative analyses of metal produced by these processes are given.

The fabrication of beryllium covers a very wide field, and Chapter 4 is accordingly divided into eight separate sections, mostly by separate authors. Powder metallurgy and melting methods are discussed, followed by the usual fabrication processes, joining and surface treatment methods. One section deals with the forging of beryllium powder contained in a sealed steel can, and shows the reduction in weight of metal required by this process, for a number of components, over the press-sintered block forged in the conventional way. Detailed data, including tho resultant mechanical properties, are given for a number of possible shapes. The section on forging of solid billets discusses the effect of preferred orientation, and indicates that dispersion hardening by beryllium oxide may eliminate variations in mechanical properties of such forgings when tested at room temperatiure.

Joining processes are obviously of considerable import, ance in the use of a metal such as beryllium, as only portions of an airframe, space vehicle, or nuclear assembly can be manufactured from this metal. Joining is taken here to include mechanical fasteners, such as screws, studs or rivets, and adhesive bonding with synthetic resins, in addition to the more common brazing, soldering and welding. Photographs of components joined by all: such methods are included in the text, together with a table of approximate mechanical strength achieved by oach at ambient temperature.

The influence of the surface on the mechanical strength of beryllium products is of considerable importance. Surface treatments and coatings are very useful in preventing brittle failure or in achieving optimum utilization of properties, so that etching, electroplating, anodizing, and cementation processes have been studied more extensively for beryllium than for some more conventional materials. The economic value attached to these rart: metals so recently exploited (or to components made from them) is such that a full knowledge of the chrmical, 